\title{
Re-inventing the fiber-optic textbook: a proposal
}

Jeff Hecht, Deborah Hecht, Ahsan Chowdary, Nicholas Massa

Jeff Hecht, Deborah Hecht, Ahsan Chowdary, Nicholas Massa, "Re-inventing the fiber-optic textbook: a proposal," Proc. SPIE 9946, Optics Education and Outreach IV, 99460M (27 September 2016); doi: 10.1117/12.2238014

SPIE Event: SPIE Optical Engineering + Applications, 2016, San Diego, California, United States 


\title{
Re-inventing the fiber-optic textbook: A proposal
}

\author{
Jeff Hecht**a, Deborah Hecht ${ }^{\mathrm{b}}$, Ahsan Chowdary ${ }^{\mathrm{c}}$, Nicholas Massa ${ }^{\mathrm{d}}$
}

${ }^{\mathrm{a}}$ Hecht Associates, 525 Auburn St., Auburndale, MA USA 02466; ${ }^{\mathrm{b}}$ Center for the Advanced Study

of Education, the Graduate Center, City University of New York, 365 Fifth Ave., New York, NY

USA, 10016; ${ }^{\circ}$ Technology Department, Niagara College Canada, 300 Woodlawn Rd, Welland, Ontario, Canada L3C 7L3; Springfield Technical Community College, One Armory Square Suite 1, P.O. Box 9000. Springfield, MA USA 01102-9000

\begin{abstract}
It's time to reinvent the textbook to meet the needs of today's students, educators, and self-study readers. Students aren't buying them, and authors and publishers have slowed or stopped revising them keep up with new technology and new pedagogy. We want to demonstrate new possibilities by completely overhauling Understanding Fiber Optics, an introduction to fiber optics originally written by J.H. for self-study and later republished as a textbook for technician training. After five editions that sold over 100,000 copies, its page count nearly doubled and its price soared more than tenfold from its original $\$ 16.95$.

We envision a modular structure to meet the needs of students and instructors. Basic concepts will be covered at an introductory level in a "core book" of some 200-250 pages, suitable for self-study, STEM programs at the high school level, and technician training. Additional separate modules primarily intended for instructors will cover details, such as how to install connectors. All materials will be distributed electronically at low cost, and will include interactive demonstrations, animations, simulations, and audio and video supplements explaining key concepts. Our goal is to keep the best aspects of a well-written and well-illustrated textbook, take advantage of new tools for presenting material to students, and make the whole package readily accessible and affordable to students, instructors, and anyone else wanting a working knowledge of fiber optics.
\end{abstract}

We are developing a proposal to achieve these goals, and looking for partners to help us develop, test and evaluate instructional materials.

Keywords: Fiber optics, education, textbook, technician training, interactive learning, modular texts

\section{INTRODUCTION}

Textbooks have been the backbones of science, technology, engineering and mathematics (STEM) courses for generations. But science, technology, engineering and math textbooks have come upon hard times, especially at the technician and undergraduate levels.

The problem most painfully evident to students and their parents is the cost of textbooks. The National Association of College stores that the average price of a new textbook in 2015 was over $\$ 80$, and that used textbook prices averaged $\$ 60 .{ }^{1}$ Textbooks for STEM courses were found to be among the most expensive of all subject areas in an analysis of costs at the University of Virginia. ${ }^{2}$ The same study found that textbook prices had risen $812 \%$ since 1978, more than triple the consumer price index. The College Board recommends students in four-year public colleges budget $\$ 1,298$ a year for textbooks. ${ }^{3}$ Students react to high textbook costs by not buying them or by avoiding courses with particularly expensive textbooks. A 2013 survey found that $65 \%$ of students did not buy assigned textbooks because of their high prices. $^{4}$ Many STEM instructors now hesitate to assign expensive textbooks because of student complaints, but find only limited options for affordable, high-quality and up-to-date STEM textbooks.

*jeff@jeffhecht.com; phone 1617 965-3834; jeffhecht.com

Optics Education and Outreach IV, edited by G. Groot Gregory, Proc. of SPIE Vol. 9946, 99460M

(C) 2016 SPIE · CCC code: $0277-786 X / 16 / \$ 18 \cdot$ doi: $10.1117 / 12.2238014$ 
Textbooks also suffer from other problems. Publishing pressures for frequent new editions and additional features tend to bulk them up, to the point where students -- especially at the technician level -- find their sheer size intimidating. On the other hand, when students are priced out of the new textbook market, sales suffer, and publishers may stop offering books on important topics because they can't sell enough copies to make a profit.

The lead author (J. H.) has seen these changes first-hand as the author of Understanding Fiber Optics. The first edition was a paperback for self-study published in 1987 with a list price of $\$ 16.95$, and updated in 1993. A few years later, it was converted to a textbook and published in hardcover with two revisions. The final fifth edition carried a list price close to $\$ 100$ when it was published in 2005 . and the list price was approaching $\$ 180$ when it was taken out of print in 2015. The author has since self-published the fifth edition in print and PDF electronic editions.

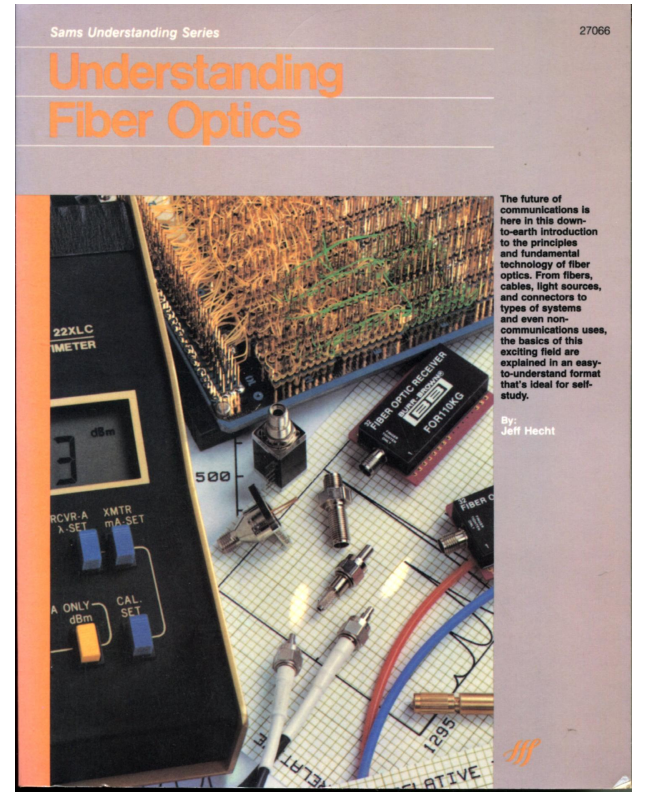

Figure 1: The first edition of Understanding Fiber Optics initially sold for $\$ 16.95$, had 450 pages, and included 20 chapters. The publisher promoted self-study on the cover.

Our collective experience and feedback from others tells us that textbooks can still play an important role in fiber-optic training in specific and STEM education in general. But to do so they must be re-invented to better match the needs of students and instructors. One obvious concern is affordability. Another making instructional material more accessible and less intimidating in approach, subject matter and size. It also should be tied to real-world applications that are relevant for rapidly evolving technology.

To meet these goals, we envision producing a "core book" covering fundamental concepts of fiber optics at an introductory level. It will be much smaller than the current 30-chapter, 800-page fifth edition, and written in a userfriendly style to inspire interest while explaining fundamental concepts. We also will supply a collection of modules to cover more advanced materials and specific topics in more detail. Both the core text and modules will include relevant interactive and video material including demonstrations, simulations and explainers.

We believe this approach can improve formal fiber-optic instruction, and fit a broader range of needs, including selfstudy at the secondary level and above, training modules for in-service education, resources for technicians in other fields who need to work with fiber optics, and generally making fiber optics training more accessible to people from diverse backgrounds.

The balance of this paper describes existing problems, and our plans for addressing them in somewhat more detail. It written from the perspective of people who have spent years working to help people understand fiber optics, and want to improve the process for the coming generations of students. 


\section{THE TEXTBOOK PROBLEM}

Textbook publishing has been caught in destructive cycles as publishers try to protect their profit margins against threats such as sales of used textbooks. The threat of used books has increased with development of online book stores, which allow students to quickly locate any copies available anywhere within reasonable shipping distance. Likewise, students finished with a textbook can easily resell it either directly to another student or to a reseller.

Periodic updates are essential in STEM fields to keep up with advances in science and technology. But for many years publishers have pushed for frequent updates of textbooks in all fields to make used copies obsolete. The standard revision cycle as of 2009 for college textbooks across all fields was three to four years, a University of Michigan study reported. At that time, used textbooks sold for about half the price of new ones. The Michigan report also noted that $76 \%$ of California faculty felt new editions were justified less than half the time. ${ }^{5}$

Publishers also ask authors to provide supplemental material not available in earlier editions. Much of this supplemental instructional material is software and workbooks bundled with the book, but some is included in the book. In my (J.H.) experience as an author publishers have always asked for addition of new material, but rarely if ever asked for removal of obsolete material, helping to bulk up books with material of little use. It also leads to higher prices. The Michigan survey cited instances where bundling supplements doubled the price of a textbook. Publishers told the General Accountability Office that they increased their investments in supplementary material such as self-assessment tools and web-based tutorials at the behest of instructors. ${ }^{6}$ But a student research group found that $65 \%$ of faculty rarely or never used the bundled materials in courses. ${ }^{7}$

The Michigan report also points out that the textbook market is subject to unusual economics because the faculty who select textbook get free examination copies, but it's the students who have to pay for the books. R. Preston McAfee, an economist formerly at Caltech, compared the "moral hazards" of professors specifying textbooks to physicians prescribing medicine -- neither has to pay the costs associated with their decisions. In 2008 McAfee told the New York Times, "This market is not working very well -- except for the shareholders in the textbook publishers." ${ }^{8} \mathrm{He}$ also chose to make his textbook Introduction to Economic available for free download at the Open Textbook Library.'

Students are taking other measures. A group of students may pool their money to buy a textbook they all share. Others now rent copies of textbooks, and return them at the end of a course. Some scan printed copies and post them on filesharing web sites, where anyone can download them. A 2015 study by the National Association of College stories found that average college student spending of $\$ 563$ on textbooks in the 2014-2015 year was a $20 \%$ drop from the 2007-2008 years, despite steady price increases.

This raises tensions among key players in the textbook business. Publishers and authors complain of digital piracy, whilst students and educators complain of exorbitant pricing. Concern about digital piracy leads some publishers to refuse to publish electronic editions of textbooks (e.g. Understanding Fiber Optics). Many others copy-protect their electronic editions and price them at 60 to $80 \%$ of the price of the print edition.

Publishers are feeling squeezed. As textbook sales slow, they have shifted from the conventional practice of printing large numbers of books at once to using "print on demand," a photocopying technology that prints one paperback copy at a time. That cuts their unit costs and inventory handling, but the print quality and binding are inferior to conventional printing. (The former publisher did this with the fifth edition of Understanding Fiber Optics.) As unit sales drop, publishers also may increase the list price of older by a certain fraction each year in hope of maximizing profits because few new copies are available.

Another change in the commercial textbook market is the increasing use of course packs rather than standard textbooks. These are collections of material from a variety of sources, chosen by instructors to customize their courses. The flexibility is valuable for instructors because it helps them match their course material to their students' needs, without overwhelming them with hundreds of pages of material that they won't need in the course. It is a mixed blessing for publishers and authors. They can earn additional revenue from an older book by licensing the use of sections in course packs, but they may not be able to match the revenue from book sales.

There has been some interest in what are called "open textbooks," posted on the Internet under Creative Commons or similar licenses that allow free non-commercial distribution. This is an interesting alternative, strongly advocated by the "Make Textbooks Affordable" program of The Student PIRGS (public interest research groups), which claims it could 
save students billions of dollars a year. ${ }^{10}$ Many books are posted at Open Library sites, but the number remains limited. ${ }^{11}$ A key problem is finding funding for authors to write books.

It is hard to assess the impact of these commercial trends without detailed figures on textbook sales, course use, and enrollment. Typically sales decay steadily from the first year, as shown in Table 1 for unit sales of the fifth edition of Understanding Fiber Optics over 10 years until the original publisher took it out of print. You can see why a publisher would want a new edition every few years to boost sales. (We have no data on number of students enrolled in courses using the book, so we cannot estimate sales of used copies.) By 2014 sales had dropped to a point where the publisher did not consider a new edition commercially viable, a decision that also reflected changes in their marketing strategy.

Table 1. Unit sales of fifth edition of Understanding Fiber Optics.

\begin{tabular}{|l|l|}
\hline \multicolumn{1}{|c|}{ Year } & \multicolumn{1}{c|}{ Unit Sales } \\
\hline 2005 & 1999 \\
\hline 2006 & 712 \\
\hline 2007 & 697 \\
\hline 2008 & 402 \\
\hline 2009 & 473 \\
\hline 2010 & 362 \\
\hline 2011 & 231 \\
\hline 2012 & 170 \\
\hline 2013 & 108 \\
\hline 2014 & 129 \\
\hline
\end{tabular}

The fiber-optic textbook market has suffered in the aftermath of the bubble. Several other fiber-optic texts were published between 1998 and 2006, but most have not been revised. But there is still a need for a current textbook, particularly at the technician level. As an Amazon reviewer noted in giving the book four stars: "There are some strong texts appropriate for graduate students, but if they lack a knowledge of partial differential equations and in particular Bessel Functions, students will probably get lost." ${ }^{2}$

\section{A NEW MODULAR STYLE OF TEXTBOOKS}

To reinvent the textbook, we are looking both to past successes and new opportunities. We look back to popular books that introduced readers to science and technology in the past. We look forward to the use of new technology to better present, illustrate, animate and demonstrate concepts, and to make information more accessible to a diverse population of everyone. Our central building blocks are the core book and instructional modules that accompany it. Together they can present the essential material from a textbook like Understanding Fiber Optics in are more accessible and less costly. They also can provide additional information students need that typically is not available in textbooks, such as information on careers in fiber-optic technology.

\subsection{The Core Book Concept}

The core book will be an introduction to the fundamentals of fiber optics, made more interesting by weaving stories and neat ideas into the fundamentals. It will be written to be accessible for everyone, starting with basic concepts and working up to more advanced ideas in an interesting way. It should be inspirational and fun, to motivate readers, as well as accessible. We plan it to be 200-250 pages long, with details to be covered in supplementary modules.

Our inspiration is remembering popular science books of the past that introduced hobbyists, high-school students, and our younger selves to the wonders of science and technology. Isaac Asimov, best remembered today for his science fiction, actually wrote more books popularizing science for the general reader. His storytelling skills and gift for clear 
and simple explanation earned him wide recognition. J.H. remembers first learning about laser communications from an Asimov essay. ${ }^{13}$

Similar books introduced and explained new technologies. Forrest M. Mims III wrote a series of hobbyist guides to electronics and computing. B. K. Johnson's Optics \& Optical Instruments was a favorite introduction to optics. Reprinted in paperback by Dover in 1960, it's still in print. They were perfect companions for a kid with an electronics kit or a set of lenses. The old Howard W. Sams publishing company was famed for self-study guides on for electronics hobbyists, radio amateurs, and technicians. Companies such as RCA and Texas Instruments published their own self-study guides to explain how their electronic devices worked. J. H. wrote the first edition of Understanding Fiber Optics thinking of those models for Sams, which published it in a \$17.95 paperback in 1987.

Much can be learned from examining how these popular science books present and share information. They are written to be engaging and draw the reader in. They treat the reader as a partner, not someone in need of schooling. They can be discussed in class, at a dinner party, or in a garage workshop. While these books often lack explicit learning objectives, pedagogical suggestions for teachers, and "what have you learned?" questions, they often succeed in explaining science and technology with clear writing, simple illustrations, and little or no mathematics.

The core book will take the best parts of that old model and build on it to cover the central concepts of fiber optics and its applications. We can take advantage of digital technology to supplement simple illustrations with video clips, animations, and interactive material. We can help readers with the minimal math -- nothing above algebra or geometry -by using simulations to show what the math means, and bring total internal reflection to life. We'll talk through examples and tell stories of how fiber optics solved problems and how people work with fiber optics. And we will tell where and how people use fiber optics and what sorts of jobs it does in fields from medicine to astronomy, and from space to the bottom of the ocean.

We plan to core book to be a multipurpose tool for learning about fiber optics. It could be a resource for secondary school teachers, a self-study tool for students interested in science and technology, a general STEM library resource, or part of a technology training program. It could be a centerpiece for an introductory fiber-optics course for technicians, in community college or in a union program for apprentice electricians. It could be an in-service education tool for the many technicians who find themselves having to work without formal training, or background reading to help undergraduate students deal with upper-level textbooks.

The core book will not contain everything anyone might want to know about fiber optics, but it will serve as an introduction. For further information, readers and instructors can turn to separate modules developed along with the core book to provide more details, explain laboratory exercises, or learn specific skills.

\subsection{Modules and Other Supplementary Material}

Conventional textbooks often try to package everything instructors might want to teach or students might need to learn into a single package. That approach has drawbacks beyond its effect on textbook pricing. It packs far too much information to be covered in a single semester course into the book, often leaving students feeling that their course was incomplete or grumbling that they had to pay for unneeded material. Although a comprehensive textbook can make a good future reference, its sheer bulk can frighten students, especially at the technician level.

To better serve both students and instructors we will take most detailed information out of the original book and package it in digitally distributed modules that instructors can pick and choose for their classes. For example, the core book would describe a few key measurements concepts, such as attenuation and measurements on a decibel scale, which are widely used and essential background for understanding other explanations. But details of optical measurement units in general and fiber-optic measurements in particular would be treated in separate modules. Likewise, the core book would explain the basic concepts of splices, connectors and couplers, but the details of how they are assembled and used will be covered in modules. Modules also would include laboratory exercise, both physical laboratory units and simulations to demonstrate specific concepts such as dispersion and error correction. Other modules could cover specific applications, such as fiber-optic bundles for imaging in endoscopes. Modules will contain video demonstrations, simulations, animations and other interactive media as needed.

The specifics of these modules are still to be decided. We will develop many modules based on the original book, and some additional modules. These will cover a range of fiber-optic applications as well as fiber-optic components and devices. We also will develop modules illustrating career options, from troubleshooting fiber-optic communication networks to using fiber-optic equipment for sensing, medicine, or astronomical observations. One possibility is a series 
of interviews with technicians in various stages of their careers, talking about their jobs, their adventures in the field, and long-term career options.

We will encourage instructors and others to develop and supply additional modules. For example a company might develop a module describing how to install fiber-to-the-home equipment that could also be used to illustrate how such systems work.

Many modules could be used outside of courses specifically on fiber optics. For example, a modules on laser beam delivery could be used in a course on industrial lasers. A module on gastroscopes, endoscopes, and colonoscopes could be used in a course on medical imaging and instrumentation. A module on fiber sensing could be used to show how bridges could be instrumented to assess their stability in a course on civil engineering. A module on fiber cables could be used in a communications technology class. The modules also could be a resource for continuing education programs or for self-study by people moving into new jobs involving fiber optics.

Using modules in conjunction with the core book would combine important features of traditional textbooks and course packs. The core book would give a uniform overview of the field with a consistent terminology and structured approach. The modules would give instructors the flexibility to focus on the needs of students in particular programs. For example, programs for communications technicians, medical technicians, or manufacturing technicians could all use the core book as a resource, but each one would use an appropriate selection of modules to focus on fiber-optic applications in communications, medicine, or manufacturing.

\section{FUTURE PLANS}

Our ideas have grown from years of experience in writing about and teaching fiber optics. We are writing a proposal for a National Science Foundation grant to develop the core book and modules, then to systematically test and evaluate them as tools for students, instructors and self-study. NSF support is vital to help us prepare and distribute the material at no cost during the development stage. We will also explore options for keeping that material available and up to date in the future at minimal or no cost to students.

Our current plans call for a three-year project to develop, test and disseminate text and web-based materials including animations, simulations, videos, assessments and teacher instructions. During the first year we will adapt material from the existing Understanding Fiber Optics, and use that base for initial testing by members of the development team. Those test results will be used to revise the first batch of material, and in preparing additional material. In the second year we plan to begin feasibility testing and more systematic testing of the educational impact, as well as continue preparing additional material. Classroom testing will help us optimize the material and assure it meets student and instructor needs for courses, and advances students along their career path. Year 2 will include tests by instructors who are not part of the development process. Lessons learned from that testing will be fed back into revisions. In the third year, we will undertake new field trials with instructors new to the program, and disseminate materials more widely, with some ongoing revision and addition of further modules as needed.

Research and evaluation on education impact will be an integral part of the study, starting in the first year and ramping up as the project progresses. Data collected during the project will be used to assess and optimize the development process and materials. Our overall evaluation will focus on how students and teachers use and learn from the materials, including their knowledge of content, attitudes about fiber optics, and career awareness.

We are looking for people and institutions to work and collaborate with us on this project. We want to involve the optical education community to get the best possible feedback on what students, instructors, and the community need. We also want to make sure the final product is made broadly available at an affordable price, so the final package can be used. For the longer term, we want to develop a maintenance and updating process to keep the re-invented textbook current for many years in the future.

\section{REFERENCES}

[1] National Association of College Stores, "Higher Education Retail Market Facts and Figures," http://www.nacs.org/research/industrystatistics/higheredfactsfigures.aspx 
[2] Kopf, Dan, "Which major has the most expensive textbooks," Priceonomics (Aug 24, 2015) http://priceonomics.com/which-major-has-the-most-expensive-textbooks/

[3] Bigfuture, "Quick guide: college costs," https://bigfuture.collegeboard.org/pay-for-college/college-costs/quick-guidecollege-costs

[4] Grasgreen, Allie, "Options don't stem textbook woes," (January 28, 2014), Inside Higher Ed

https://www.insidehighered.com/news/2014/01/28/textbook-prices-still-crippling-students-report-says

[5] Nicholls, Natsuko Hayashi, "A background study of the context of Michigan initiatives with an eye toward launching a library-based college textbook publishing program," University of Michigan Library, (April 2009),

http://www.lib.umich.edu/files/SPOTextbookBackground.pdf

[6] Government Accountability Office (GAO), 2005. "College Textbooks: Enhanced Offerings Appear to Drive Recent Price Increases," Washington, D.C. Available at

http://www.gao.gov/new.items/d05806.pdf

[7] Fairchild, Merriah, "Rip-off 101: How the Current Practices of Textbook Industry Drive Up the

Cost of College Textbooks," 2004, CALPIRG Higher Education Project,

http://studentpirgs.org/sites/student/files/resources/04\%20-textbookripoff.pdf

[8] Cohen, Noam, "Don't buy that textbook, download it free," New York Times, Sept 14, 2008, http://www.nytimes.com/2008/09/15/technology/15link.html? r $r=0$

[9] McAfee, Preston, and Lewis, Tracy, "Introduction to Economic Analysis,"

https://open.umn.edu/opentextbooks/BookDetail.aspx?bookId=47

[10] Senack, Ethan, "Open Textbooks: The Billion-Dollar Solution," The Student PIRGS, February 2015

http://studentpirgs.org/sites/student/files/reports/The\%20Billion\%20Dollar\%20Solution.pdf

[11] Open Textbook Library, http://open.umn.edu/opentextbooks/

[12] JD, "The best affordable book on fiber optics," https://www.amazon.com/review/R1IL78U26SBSSI

[13] Asimov, Isaac, "The Light Fantastic," Magazine of Fantasy \& Science Fiction, August 1962, pages 53-63 